\title{
Growth and development of rats artificially reared on rats' milk or rats' milk/milk-substitute combinations
}

\author{
BY J. TONKISS, J. L. SMART AND R. F. MASSEY \\ Department of Child Health, University of Manchester, The Medical School, \\ Oxford Road, Manchester M13 9PT
}

(Received 14 March 1986 - Accepted 1 August 1986)

1. Rat pups were artificially reared (AR) from post-natal day 5 by intermittent gastric infusion. Mother-reared (MR) siblings served as controls. Fourteen measures of body and organ growth were taken at the end of each experiment.

2. In Expt 1, two batches of pups were given rats' milk only, obtained by manual expression from anaesthetized dams.

3. The first batch, reared to $12 \mathrm{~d}$, grew less well than the MR group, probably because they received too little milk. However, relative to body-weight, organ weights were as great or greater than those of MR pups, except for heart weight. The second batch, given more milk and reared to $20 \mathrm{~d}$, showed no deficits in organ or body-weights, but excesses in kidney, gastrocnemius muscle, stomach and caecum weights. There were no losses from 'bloat', a condition of gastrointestinal distention often encountered in artificial rearing with milk substitutes.

4. Obtaining rats' milk is extremely labour-intensive and in Expt 2, more economical regimens were devised in which pups were started off on expressed rats' milk and then changed to a milk substitute resembling rats' milk in composition, either abruptly at $12 \mathrm{~d}$ or gradually between 8 and $17 \mathrm{~d}$.

5 . Both regimens were successful, in that there were no losses from bloat and most measures of growth were at least as great as in the MR group. Only heart weight was lower in both AR groups and adrenal weight in the abruptly changed AR group. The weights of the stomach and caecum and the length of the small intestine were all high in both AR groups.

6. It is concluded that giving rat pups expressed rats' milk for the first few days of artificial rearing largely avoids the problem of bloat and results in satisfactory growth.

A method of rearing rats without their mothers, from just a few postnatal days of age until weaning, has been described by Messer et al. (1969) and modified subsequently by Hall (1975). Briefly, the procedure involves fitting the pup with a gastric cannula through which a milk-substitute can be infused. The technique is potentially very useful in a variety of developmental studies, e.g. nutritional, pharmacological and psychological, since it offers precise control over various aspects of the early environment.

Unfortunately there are problems with the technique which greatly limit its usefulness. Prime amongst these is the occurrence of a condition of abdominal distention termed 'bloat', which develops in some, but not all, animals when milk substitutes are given in volumes approximating the intake of naturally reared pups (Diaz et al. 1980; Smart et al. 1984). Bloat appears to occur with all of the milk substitutes that have been tried so far and, typically, it develops within $2-5 \mathrm{~d}$ of the start of artificial rearing. Bloated pups may recover if the rate of milk infusion is greatly reduced but this, of course, results in retarded growth. In order to avoid bloat we have sometimes settled for sub-optimal growth and have given lower volumes of milk substitute than we would have wished right from the start of artificial rearing (Smart et al. 1984; Tonkiss et al. 1985). Clearly this is unsatisfactory.

Another problem is that even when normal growth in body-weight has been attained in rat pups artificially reared on milk substitutes, further investigation has revealed that the growth of several of the constituent organs has been abnormal (Diaz et al. 1981, 1982; Smart et al. 1983, 1984). This should probably not have been unexpected in experiments with the orginal milk substitute (Messer et al. 1969) which is very high in carbohydrate and low in protein compared with rats' milk and is known to give rise to atypical levels of blood 
metabolites derived from fat, carbohydrate and protein (Sonnenberg et al. 1982). What is more surprising is that use of a milk substitute which resembles rats' milk much more closely in composition also results in some abnormalities of organ growth (Smart et al. 1984). The question arises, to what extent are bloat and abnormal organ growth a function of deficiencies in the composition of the milk substitute or of other aspects of the artificial rearing procedure?

The findings of the present Expt 1, in which rat pups were artificially reared on expressed rats' milk, indicated that milk composition was by far the more important factor. Since obtaining sufficient rats' milk for artificial rearing is almost prohibitively expensive in terms of time and effort, Expt 2 was undertaken to assess the efficacy of a more economical regimen. This experiment involved starting artificial rearing on expressed rats' milk and changing either abruptly or gradually to a milk substitute.

\section{METHODS \\ Milking procedure}

Rats' milk was obtained from dams nursing litters $7-20 \mathrm{~d}$ old. The dams were milked under anaesthesia (sodium pentobarbitone, $26.4 \mathrm{mg} / \mathrm{kg}$ ), at least $16 \mathrm{~h}$ after separation from their litters. Pups were kept warm on a water bath during the period of separation and were returned to their mothers when they had regained consciousness. Milk was expressed manually into a tube fitted over the teat, under negative pressure. Most mothers were milked more than once, allowing at least $2 \mathrm{~d}$ between successive milkings. When sufficient milk had been collected for a rearing run, it was processed for use. Processing consisted of pooling all the milk samples, mixing the milk, dividing it into $10 \mathrm{ml}$ quantities and then homogenizing it by sonication. Each sample was sonicated (setting 6-7, MSE sonicator) for $6 \times 10 \mathrm{~s}$ periods with 10-s intervals between successive sonications. This procedure served to disperse the milk fat which would otherwise separate out to form a distinct 'cream' layer.

\section{General}

On the fifth postnatal day, male rats of a black and white hooded Lister stock were fitted with a gastric cannula by the method of Hall (1975). The rearing procedure and conditions have been described in detail previously (Smart et al. 1983). Briefly, from the day of cannulation until the rats were killed, artificially reared (AR) rats were given rats' milk, a milk substitute closely resembling the composition of rats' milk (milk A of Smart et al. 1984), or mixtures of the two 'milks', by intermittent gastric infusion $(0.25 \mathrm{~h}$ infusion every h). The mean daily volumes of 'milk' infused per pup are shown in Figs 1 and 2 (pp. 6 and 7). On postnatal day 5, following cannulation of the AR rats, the number of pups remaining with the mother in each litter was reduced to nine or ten. These litters formed the mother-reared (MR) control group. The number of rats taken for autopsy from each group is given in Tables 1 (p. 7) and 3 (p. 9). No more than three pups were taken from any one litter for inclusion in the same experimental group.

\section{Expt 1}

In Expt 1, two batches of rats were reared on expressed rats' milk. The first batch was reared from days 5 to 12 , and the second from days 5 to 20 , at the end of which periods they were killed for autopsy. Rats artificially reared on rats' milk only are termed ARR. 


\section{Expt 2}

In Expt 2, rats were reared from days 5 to 20 on expressed rats' milk and a milk substitute, milk A (N. S. Auestad, J. D. Bergstrom, Y. H. Ha and J. Edmond, unpublished results), the gross composition of which is close to that published for rats' milk (Dymsza et al. 1964; composition of milk A $(\mathrm{g} / \mathrm{l})$ : protein 79 , carbohydrate 36 , fat 102). Further information on the preparation and composition of milk $A$ is given by Smart et al. (1984).

Two different regimens were used. (1) Abrupt change: from days 5 to 12 the rats were given expressed rats' milk ( $R$ ) only, and thereafter were transferred to milk A only. (2) Gradual change: from days 5 to 7 the rats were given $R$ only; days 8 to 10 , a mixture of $\mathrm{R}$ and $\mathrm{A}(75: 25, \mathrm{v} / \mathrm{v})$; days 11 to $13, \mathrm{R}$ and $\mathrm{A}(50: 50, \mathrm{v} / \mathrm{v})$; days 14 to $16, \mathrm{R}$ and $\mathrm{A}(25$ : $75 \mathrm{v} / \mathrm{v}$ ); days 17 to 20 , A only. Rats reared by the abrupt and gradual change regimens are termed $\mathrm{ARa}$ and $\mathrm{ARg}$ respectively.

\section{Measurements}

Body-weight was recorded at day 5 , day 8 and every $4 \mathrm{~d}$ thereafter for MR rats, and daily from day 5 for AR rats. From day 11 all rats were inspected daily for eye-opening.

On the day of autopsy, the rats were anaesthetized, weighed and then killed by exsanguination. Liver, heart, kidneys, gastrocnemius muscle, brain, epididymal fat pads, spleen, adrenals, stomach and caecum were all dissected out, trimmed of fat and connective tissue and weighed. Stomach and caecum were cut open, washed in saline ( $9 \mathrm{~g}$ sodium chloride/l) and lightly blotted before weighing. Body length and small and large intestine lengths were also measured. Body length was determined by placing the rat dorsally on millimetre graph paper and measuring the length from nose to anus. Intestine lengths were measured with the organ suspended vertically under its own weight. An additional measure was taken for some of the rats; that of weight-for-length of samples of proximal and distal small intestine. Lengths of small intestine were removed $10 \mathrm{~mm}$ from the proximal end and $10 \mathrm{~mm}$ from the distal end of the small intestine using a microscope slide (length $76 \mathrm{~mm}$ ) as a template. These samples were cut open longitudinally, washed in saline, and blotted and weighed.

\section{Statistics}

Body-weight was analysed as follows. For Expt 2, and the rats reared to day 20 in Expt 1, a two-way analysis of variance (age $\times$ group) with one repeated measure (age) was used. A similar analysis was not carried out on rats reared to day 12 in Expt 1 because of absence of some values for day 5; instead the groups were compared at 8 and $12 \mathrm{~d}$ using Student's $t$ test. For MR rats, the mean body-weight of the male pups in each litter was used as the unit for analysis. Organ weights and lengths were compared between groups by $t$ test.

\section{RESULTS}

\section{Survival and development}

Expt 1 . All of the ARR group reared to $12 \mathrm{~d}$ survived and none showed bloat. Of those ARR rats which were being artificially reared to $20 \mathrm{~d}$, three were lost, but not due to bloat. Two did show some signs of bloat, but both recovered following a brief reduction in the volume of milk infused. No bloat was seen in rats of the MR groups, although diarrhoea was present in one litter. Two litters of MR rats each lost a single pup. The cause was not identified.

There was no difference between ARR and MR rats in the age at which both eyes were found to have opened. 
Expt 2. All ARa rats and all but one of the ARg group survived. The only loss was for non-nutritional reasons. All MR rats survived and no bloat was observed in any MR or AR pup.

There was no difference in the age at which both eyes were found to have opened in rats of the ARa and ARg groups. Their modal age of eye-opening, $14 \mathrm{~d}$, was the same as that normally observed in MR rats of this stock.

\section{Growth in body-weight}

Expt 1. Fig. 1 illustrates the growth curves of ARR rats and their MR controls. ARR rats which were being reared to $12 \mathrm{~d}$ weighed significantly less than the MR controls on day $8(t 2.765$, df $5, P<0.05)$ and day $12(t 5.524$, df $5, P<0.01)$. In contrast, there was no overall difference in body-weight between those ARR and MR rats reared to day 20 $\left(F_{1,9}=0.00\right.$, not significant $)$. Body-weight increased with age $\left(F_{4,36}=674.37, P<0.001\right)$ but the growth trajectories of the two groups were different, as indicated by the significant age $\times$ group interaction $\left(F_{4,36}=5 \cdot 32, P<0.01\right)$.

Expt 2. Fig. 2 illustrates the growth curves of $\mathrm{ARa}, \mathrm{ARg}$ and $\mathrm{MR}$ rats. Analysis of variance carried out on the body-weight data of all three groups revealed significant effects of age $\left(F_{4,72}=2538.95, P<0.001\right)$ and group $\left(F_{2,18}=7.05, P<0.01\right)$ and an interaction between age and group $\left(F_{8,72}=3 \cdot 60, P<0.05\right)$. When the groups were compared individually, there were no differences between the two artificially reared groups, but both the ARa and ARg groups weighed less than the MR controls $\left(F_{1,12}=12 \cdot 75, P<0.01\right.$; and $F_{1,11}=9.35, P<0.05$ respectively). Also, the growth curves of the ARa and ARg groups differed in shape from that of the MR animals (age $\times$ group interactions: $F_{4,48}=4 \cdot 62$, $P<0.01$; and $F_{4,44}=8.62, P<0.001$ respectively).

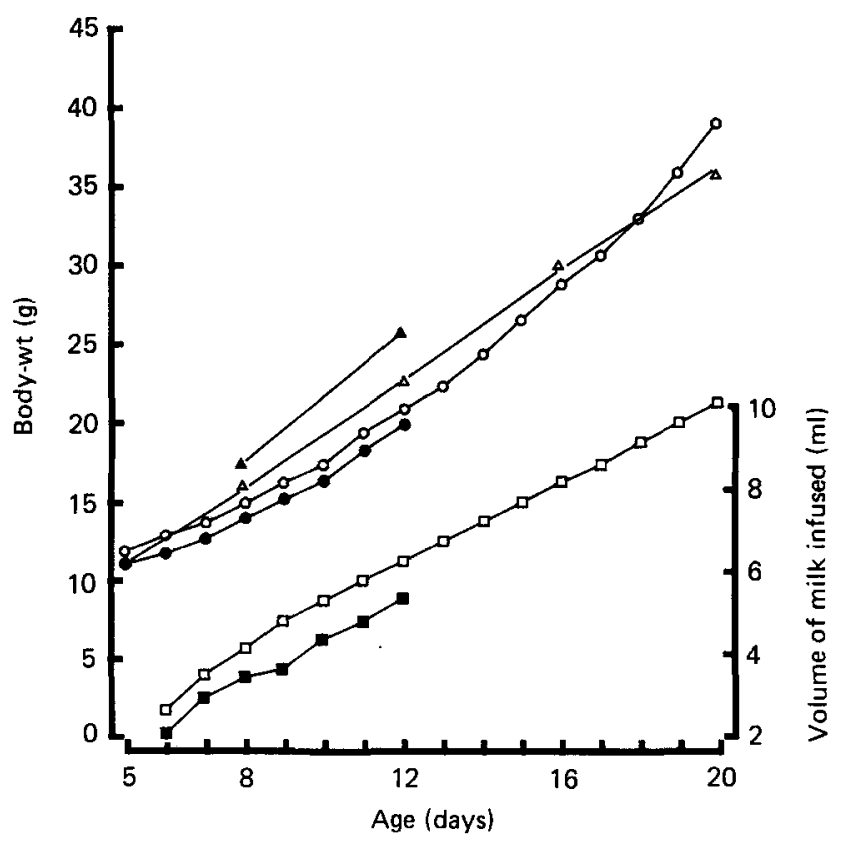

Fig. 1. Mean body-weight at different ages of rats artificially reared on rats' milk only (ARR) from 5 to $12 \mathrm{~d}(\mathrm{O})$ or 5 to $20 \mathrm{~d}(\mathrm{O})$, and their mother-reared (MR) controls ( $\Delta$ and $\triangle$ respectively). It should be noted that body-weight values at day 5 were not available for the MR rats reared to $12 \mathrm{~d}$. The volume of milk infused into the ARR rats is also illustrated ( $\square, 5-12 \mathrm{~d}$ group; $\square, 5-20 \mathrm{~d}$ group). The value at each point represents the amount infused in the previous $24 \mathrm{~h}, \mathrm{e.g}$. the amount given in the $24 \mathrm{~h}$, day $5-6$, is shown opposite day 6. 


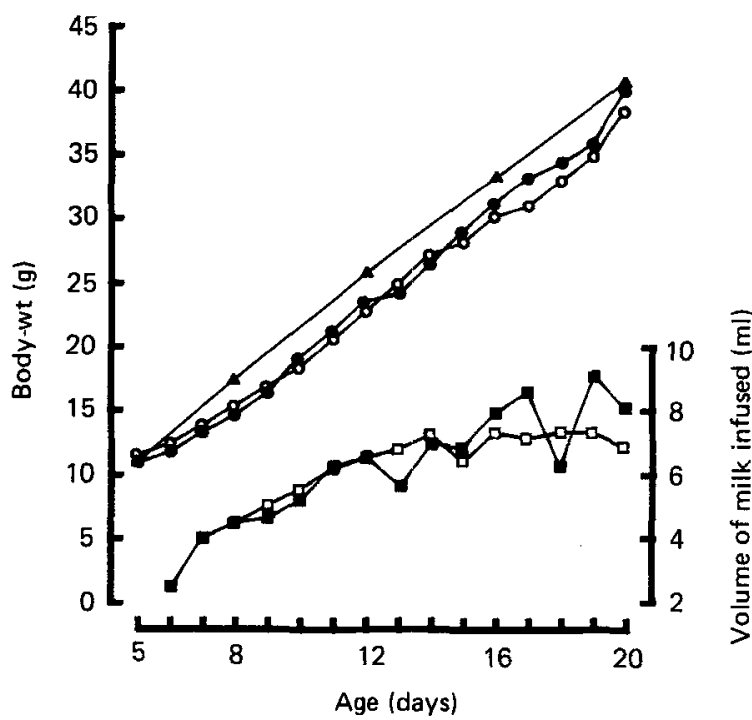

Fig. 2. Mean body-weight from 5 to $20 \mathrm{~d}$ of rats which were mother-reared $(\boldsymbol{A})$ or artificially reared on rats' milk then milk substitute, changing from one to the other either gradually between 8 and $17 \mathrm{~d}$ (ARg, ) or abruptly at $12 \mathrm{~d}(\mathrm{ARa}, \mathrm{O})$. The volume of milk infused into $\mathrm{ARg}(\boldsymbol{G})$ and $\mathrm{ARa}(\square)$ rats is also shown. The value at each point represents the amount of milk infused in the previous $24 \mathrm{~h}$, e.g. the amount given in the $24 \mathrm{~h}$, day $5-6$, is shown opposite day 6 .

Table 1. Expt 1. Body and organ measurements at 12 and $20 \mathrm{~d}$ of mother-reared $(M R)$ rats and of rats artificially reared on rats' milk $(A R R)$

(Mean values with their standard errors; no. of animals in parentheses)

\begin{tabular}{|c|c|c|c|c|c|c|c|c|}
\hline \multirow[t]{3}{*}{ Age of pups (d)... } & \multicolumn{4}{|c|}{12} & \multicolumn{4}{|c|}{20} \\
\hline & \multicolumn{2}{|c|}{$\operatorname{MR}(5)$} & \multicolumn{2}{|c|}{ ARR (5) } & \multicolumn{2}{|c|}{$\operatorname{MR}(7)$} & \multicolumn{2}{|c|}{$\operatorname{ARR}(4)$} \\
\hline & Mean & SE & Mean & SE & Mean & SE & Mean & $\mathrm{SE}$ \\
\hline Body-wt (g) & $25 \cdot 3$ & $1 \cdot 0$ & $20 \cdot 0$ & $0 \cdot 2$ & $35 \cdot 6$ & $1 \cdot 3$ & $38 \cdot 2$ & 0.7 \\
\hline Nose-rump length (mm) & $94 \cdot 5$ & $1 \cdot 4$ & $87 \cdot 7$ & $0 . \overline{8}$ & $112 \cdot 9$ & $1 \cdot 2$ & $113 \cdot 0$ & 0.5 \\
\hline Gastrocnemius muscle wt $(\mathrm{g})$ & 0.061 & 0.005 & 0.057 & 0.005 & 0.138 & 0.007 & 0.164 & 0.004 \\
\hline Epididymal fat pads wt (g) & 0.014 & 0.001 & $0 \cdot 010$ & 0.001 & 0.041 & 0.003 & $0 \cdot 044$ & 0.002 \\
\hline Brain wt $(\mathrm{g})$ & 1.064 & $0 \cdot 015$ & 0.986 & $0 \cdot 009$ & $1 \cdot 322$ & 0.018 & $1 \cdot 318$ & 0.026 \\
\hline Heart wt (g) & 0.137 & 0.002 & 0.089 & 0.002 & $0 \cdot 169$ & 0.008 & $0 \cdot 165$ & 0.003 \\
\hline Kidneys wi (g) & $0 \cdot 251$ & 0.017 & 0.243 & 0.003 & $0 \cdot 346$ & 0.011 & $0-428$ & 0.011 \\
\hline Adrenals wt (mg) & $5 \cdot 6$ & 0.4 & $4 \cdot 7$ & $0 \cdot 2$ & $11 \cdot 5$ & 0.6 & $10 \cdot 8$ & $0 \cdot 2$ \\
\hline Liver wt (g) & 0.916 & 0.049 & 0.806 & 0.021 & $1 \cdot 568$ & 0.066 & 1.694 & 0.044 \\
\hline Spleen wt (g) & $0 \cdot 151$ & 0.004 & 0.121 & 0.006 & $0 \cdot 156$ & 0.020 & $0 \cdot 183$ & 0.013 \\
\hline Stomach wt $(\mathrm{g})$ & $0 \cdot 130$ & 0.007 & $0 \cdot 129$ & 0.003 & 0.231 & 0.008 & 0.297 & 0.013 \\
\hline SI length (mm) & 350 & 6 & 361 & 10 & 437 & 17 & 464 & 23 \\
\hline Proximal SI $(\mathrm{g} / \mathrm{m})$ & - & - & - & - & $2 \cdot 6$ & 0.2 & $2 \cdot 6$ & 0.2 \\
\hline Distal SI $(\mathrm{g} / \mathrm{m})$ & - & - & - & - & $2 \cdot 7$ & $0 \cdot 2$ & $2 \cdot 9$ & 0.2 \\
\hline Caecum wt (g) & 0.037 & 0.002 & 0.037 & 0.002 & $0 \cdot 121$ & 0.008 & $0 \cdot 160$ & 0.018 \\
\hline Large intestine length (mm) & 61 & 1 & 61 & 1 & 84 & 2 & 88 & 2 \\
\hline
\end{tabular}

SI, small intestine. 
Table 2. Expt 1. Body and organ measurements (absolute values and relative values $(\mathrm{g} / \mathrm{kg}$ body-weight)) at 12 and 20 d of rats artificially reared on rats' milk (ARR) expressed as a percentage of those of mother-reared $(M R)$ rats

\begin{tabular}{|c|c|c|c|c|}
\hline \multirow[t]{3}{*}{ Age of pups (d)... } & \multirow{2}{*}{\multicolumn{2}{|c|}{$\frac{12}{\operatorname{ARR}(\% \mathrm{MR})}$}} & \multirow{2}{*}{\multicolumn{2}{|c|}{$\frac{20}{\operatorname{ARR}(\% \mathrm{MR})}$}} \\
\hline & & & & \\
\hline & $\begin{array}{l}\text { Absolute } \\
\text { values }\end{array}$ & $\begin{array}{l}\mathrm{g} / \mathrm{kg} \\
\text { body-wt }\end{array}$ & $\begin{array}{l}\text { Absolute } \\
\text { values }\end{array}$ & $\begin{array}{l}\mathrm{g} / \mathrm{kg} \\
\text { body-wt }\end{array}$ \\
\hline Body-wt & $79 * *$ & - & 107 & - \\
\hline Nose-rump length & $93^{* *}$ & - & 100 & - \\
\hline Gastrocnemius muscle wt & 94 & 118 & $119^{*}$ & $111^{*}$ \\
\hline Epididymal fat pads wt & $73^{*}$ & 92 & 108 & 102 \\
\hline Brain wt & $93^{* *}$ & $116^{* * *}$ & 100 & 92 \\
\hline Heart wt & $65^{* * *}$ & $81^{* *}$ & 98 & 91 \\
\hline Kidneys wt & 97 & $123^{* * * *}$ & $124^{* *}$ & $115^{* *}$ \\
\hline Adrenals wt & 84 & 104 & 94 & 93 \\
\hline Liver wt & 88 & $111^{*}$ & 108 & 101 \\
\hline Spleen wt & $81^{* *}$ & 101 & 117 & 110 \\
\hline Stomach wt & 99 & $126^{* * *}$ & $129^{* *}$ & $120^{* *}$ \\
\hline SI length & 103 & - & 106 & - \\
\hline Proximal SI wt/length & - & - & 99 & - \\
\hline Distal SI wt/length & - & - & 107 & - \\
\hline Caecum wt & 102 & $129^{* * *}$ & $132^{*}$ & 123 \\
\hline Large intestine length & 100 & - & 105 & - \\
\hline
\end{tabular}

SI, small intestine.

Significantly different from MR (Student's $t$ test): * $P<0.05,{ }^{* *} P<0.01$, *** $P<0.001$.

\section{Body and organ measurements}

Expt 1. ARR rats autopsied at $12 \mathrm{~d}$ showed a significant body-weight deficit of $21 \%$ compared with MR controls. No such difference was found between ARR and MR rats autopsied at $20 \mathrm{~d}$ (Table 1 ).

Organ weights have been compared between the groups in two ways. Firstly, as absolute values and, secondly, to take account of the differences in body-weight, as a proportion of body-weight (Tables 1 and 2). At $12 \mathrm{~d}$, the ARR rats displayed deficits in body length and in the weights of whole body, heart, brain, epididymal fat pads and spleen. When organ weights were expressed as a proportion of body-weight, the ARR rats were found to have relatively heavier liver, kidneys, brain, stomach and caecum. The deficit in heart weight remained statistically significant.

The ARR rats autopsied at $20 \mathrm{~d}$ showed excesses in the absolute weights of kidneys, gastrocnemius muscle, stomach and caecum. With the exception of the caecum, all these organs were also relatively heavier in the ARR rats when organ weights were expressed as a proportion of body-weight.

Expt 2. Body-weights did not differ between groups at $20 \mathrm{~d}$ and, hence, unlike Expt 1 , there was no need to calculate organ weights relative to body-weight. Whether the diet of AR rats was changed abruptly or gradually from rats' milk to milk substitute resulted in only one significant effect at autopsy: ARg rats had heavier livers than those of ARa animals (Table 3). Both AR groups differed from MR controls in heart weight (less), stomach weight, caecum weight and small intestine length (all greater). ARa rats had lighter adrenals and tended to be shorter animals than MR controls, and ARg rats tended to have heavier kidneys than the controls $(P<0 \cdot 1)$. 
Table 3. Expt 2. Body and organ measurements at 20 d of rats which were mother-reared $(M R)$ or artificially reared on rats' milk then milk substitute, changing from one to the other either gradually between 8 and $17 d(A R g)$ or abruptly at $12 d(A R a)$

(Mean values with their standard errors; no. of animals in parentheses)

\begin{tabular}{|c|c|c|c|c|c|c|}
\hline & \multicolumn{2}{|c|}{$\operatorname{MR}(6)$} & \multicolumn{2}{|c|}{$\operatorname{ARg}(7)$} & \multicolumn{2}{|c|}{ ARa (8) } \\
\hline & Mean & $\mathrm{SE}$ & Mean & SE & Mean & SE \\
\hline Body-wt (g) & $39 \cdot 7$ & 0.8 & $40 \cdot 2$ & $0 \cdot 8$ & $39 \cdot 0$ & 0.9 \\
\hline Nose-rump length (mm) & $118 \cdot 0$ & $0 \cdot 8$ & $116 \cdot 8$ & 0.6 & $115 \cdot 5$ & 1.0 \\
\hline $\begin{array}{l}\text { Gastrocnemius muscle } \\
\text { wt }(\mathrm{g})\end{array}$ & $0 \cdot 173$ & 0.004 & $0 \cdot 170$ & $0 \cdot 004$ & $0 \cdot 165$ & 0.006 \\
\hline $\begin{array}{l}\text { Epididymal fat pads } \\
\text { wt (g) }\end{array}$ & 0.049 & 0.001 & 0.047 & 0.004 & $0 \cdot 041$ & 0.005 \\
\hline Brain wt $(\mathrm{g})$ & $1 \cdot 342$ & 0.027 & $1 \cdot 312$ & 0.023 & $1 \cdot 300$ & 0.016 \\
\hline Heart wt (g) & $0 \cdot 188$ & 0.002 & $0 \cdot 165^{* *}$ & 0.006 & $0 \cdot 157^{* * *}$ & 0.004 \\
\hline Kidneys wt (g) & $0 \cdot 382$ & 0.009 & 0.409 & 0.010 & 0.392 & 0.014 \\
\hline Adrenals wt (mg) & $13 \cdot 2$ & 0.5 & $13 \cdot 1$ & 0.7 & $11 \cdot 9 *$ & $0 \cdot 4$ \\
\hline Liver wt (g) & $1 \cdot 701$ & 0.050 & $1.981 *+\dagger$ & $0 \cdot 084$ & 1.672 & 0.051 \\
\hline Spleen wt (g) & 0.144 & $0 \cdot 014$ & 0.167 & $0 \cdot 013$ & $0 \cdot 150$ & 0.008 \\
\hline Stomach wt (g) & 0.254 & 0.011 & $0.320 * * *$ & 0.007 & $0.318^{* *}$ & 0.001 \\
\hline $\begin{array}{l}\text { Small intestine } \\
\text { length }(\mathrm{mm})\end{array}$ & 467 & 15 & $553^{* *}$ & 21 & $534^{*}$ & 15 \\
\hline Caecum wt (g) & $0 \cdot 114$ & 0.008 & $0 \cdot 150^{* *}$ & 0.005 & $0 \cdot 162^{* *}$ & 0.010 \\
\hline $\begin{array}{l}\text { Large intestine length } \\
(\mathrm{mm})\end{array}$ & 82 & 2 & 86 & 1 & 87 & 2 \\
\hline
\end{tabular}

Mean values were significantly different from those for MR group (Student's $t$ test): ${ }^{*} P<0.05,{ }^{* *} P<0.01$, ***P<0.001.

Mean value was significantly different from that for ARa group (Student's $t$ test): $\uparrow \dagger P<0 \cdot 01$.

\section{DISCUSSION}

Bloat is one of the most frequent and apparently intractable problems encountered when artificially rearing rats entirely on milk substitutes (e.g. Diaz et al. 1980; Smart et al. 1984). It is particularly troublesome since it is highly likely to occur when one attempts to infuse milk substitutes in volumes approximating the milk intake of MR rats (Tonkiss et al. 1985). If one infuses smaller quantities of 'milk' in order to avoid bloat, then growth is deficient. In the present experiments in which rats' milk or rats' milk/milk substitute combinations were utilized, bloat was uncommon and never severe, and growth, although not identical in its course to that of MR rats, was such that by day 20 the body-weights of the AR and MR groups were statistically indistinguishable. Hence, the use of rats' milk in this study was effective in reducing both the incidence and severity of bloat and promoting good growth in AR rats.

Good growth in body-weight has been achieved previously using milk substitutes (Smart et al. 1983). However, it was found on autopsy at $21 \mathrm{~d}$ of age that the growth of several organs in those AR animals was abnormal. In the present Expt 2, where rats were transferred from expressed rats' milk to a milk substitute either abruptly on day 12 or gradually over the $15 \mathrm{~d}$ rearing period, there were relatively few disturbances of organ growth. The major effects were on the gastrointestinal tract. Stomach weight, caecum weight and small intestine length were all greater in the AR rats. Increases in all these measures have been noted previously in rats reared from 5 to $20 \mathrm{~d}$ entirely on the milk substitute (milk 
A) used in the present Expt 2 (Smart et al. 1984; Tonkiss et al. 1985). The question arises, to what extent are these effects due to nutritional factors or to aspects of the artificial rearing procedure itself? In Expt 1, rats artificially reared on rats' milk alone had greater than normal stomach and caecum weights (Table 2). This might tend to implicate some aspect of the artificial rearing procedure. However, rats artificially reared on a milk substitute (milk M), devised by Messer et al. (1969), have been shown to develop stomachs of similar weight to those of MR rats (Smart et al. 1983, 1984; Tonkiss et al. 1985). If some feature of the rearing procedure itself promoted increased stomach weight one would not have anticipated this finding. Clearly the situation is complex and it is possible that several factors interact to affect the growth of these organs.

In contrast, rats reared artificially on rats' milk alone did not show the overgrowth of the small intestines which is characteristic of rats reared wholly (Smart et al. 1983, 1984; Tonkiss et al. 1985) or partly (Expt 2) on milk substitutes. Dietary factors would appear, therefore, to be implicated in the excessive growth of the small intestine. Indeed, the finding that one milk substitute (milk $M$ ) has a much greater effect on small intestinal growth than another (milk A) (Smart et al. 1984; Tonkiss et al. 1985) reinforces this view.

One feature of the present study which is particularly encouraging for those of us who wish to use the AR procedure in studies of behavioural development is that brain weight was within the normal range for all groups reared to $20 \mathrm{~d}$. That the ARR rats which were killed at $12 \mathrm{~d}$ of age had lower brain weights than MR animals (Table 2) was almost certainly due to the volumes of milk they received being insufficient for the support of good growth (see Fig. 1). Low brain weight has been a consistent finding in previous studies in which milk substitutes have been used (Diaz et al., 1981, 1982; Smart et al. 1983, 1984) and it has been suggested that this may be due to non-nutritional aspects of the artificial rearing procedure; for example, deprivation of maternal and sibling contact which reduces social, thermal, tactile and other stimulation (Diaz et al. 1982). Although these factors may have some influence on brain growth, the achievement of normal brain weights in the present study indicates strongly that the provision of adequate nutrition during the 'suckling' period is of much greater importance.

An obvious limitation of using rats' milk for artificially rearing rat pups is the cost in terms of the effort and time required to obtain sufficient milk to perform a rearing run. Consider the following. It takes more than $100 \mathrm{ml}$ milk to rear one pup from 5 to $20 \mathrm{~d}$ of age. Each milking yields about $3 \mathrm{ml}$ per dam and lasts about $30 \mathrm{~min}$. Thus to rear ten animals on rats' milk requires approximately 330 milkings occupying a total of some 165 man-hours. Clearly the regimens in which the diet was changed either abruptly or gradually during AR from rats' milk to milk substitute represent a considerable advance, in that they require less than half the volume of rats' milk. It would be well worth investigating how early a change-over the pups would tolerate without encountering significant bloat and growth problems.

One cause for concern is that the rats' milk collected after $16 \mathrm{~h}$ separation of dam from litter may differ to some extent in composition from that taken by the pup in the normal situation. (A long period of separation is necessary for worthwhile volumes of milk to accumulate.) Indeed, there is evidence that such lengthy separation results in milk which is lower in fat and higher in water content than normal milk (Naismith et al. 1969). This might be the source of some of the remaining differences in growth between ARR and MR rats, for example the enlarged kidneys of the ARR animals. It could be argued that the ARR pups had to be given greater volumes of expressed (low fat) milk than the MR pups were taking of normal milk, in order to achieve similar growth in body-weight, and thus putting greater demands on the kidneys. In support of this, it is known that the kidneys of adult female rats increase in weight during lactation (Souders \& Morgan, 1957), at which 
time food and water consumption are much increased (Anderson \& Turner, 1963; Shirley, 1984). Furthermore, in the present study, the ARa and ARg groups, which had normal kidney weights at $20 \mathrm{~d}$ (Table 3 ), did not receive as great a volume of 'milk' as the ARR pups, especially in the latter stages (Figs. 1 and 2).

There would appear to be a case for analysing expressed rats' milk and, on the basis of the analysis, fortifying it appropriately before using it for artificial rearing. The addition of fat is likely to be advisable, together with fat-soluble vitamins.

The research was funded by the Medical Research Council and the National Fund for Research into Crippling Diseases. We are very grateful to Professor John Edmond and Ms Nancy Auestad for supplying us with rat milk substitute, to Dr Peter Rogers for help with milking rats, and to our dissection team, Ms Sian Nash, Ms Jenny Morris and Mr Geoffrey Carlson, for their skilled assistance.

\section{REFERENCES}

Anderson, R. R. \& Turner, C. W. (1963). Proceedings of the Society for Experimental Biology and Medicine 113, 334-336.

Diaz, J., Moore, E., Petracca, F., Schacher, J. \& Stamper, C. (1981). Physiology and Behavior 27, $1103-1105$.

Diaz, J., Moore, E., Petracca, F., Schacher, J. \& Stamper, C. (1982). Journal of Nutrition 112, 841-847.

Diaz, J., Samson, H., Kessler, D., Stamper, C., Moore, E., Robisch, E. \& Hodson, A. (1980). Pediatric Research 14, 595.

Dymsza, H. A., Czajka, D. M. \& Miller, S. A. (1964). Journal of Nutrition 84, 100-106.

Hall, W. G. (1975). Science 190, 1313-1315.

Messer, M., Thoman, E. B., Terrasa, A. G. \& Dallman, P. R. (1969). Journal of Nutrition 98, 404-410.

Naismith, D. J., Mittwoch, A. \& Platt, B. S. (1969). British Journal of Nutrition 23, 683-693.

Shirley, B. (1984). Laboratory Animal Science 34, 169-172.

Smart, J. L., Stephens, D. N. \& Katz, H. B. (1983). British Journal of Nutrition 49, 497-506.

Smart, J. L., Stephens, D. N., Tonkiss, J., Auestad, N. S. \& Edmond, J. (1984). British Journal of Nutrition 52, $227-237$.

Sonnenberg, N., Bergstrom, J. D., Ha, Y. H. \& Edmond, J. (1982). Journal of Nutrition 112, 1506-1514.

Souders, H. J. \& Morgan, A. F. (1957). American Journal of Physiology 191 (1), 1-7.

Tonkiss, J., Smart, J. L., Auestad, N. S. \& Edmond, J. (1985). Journal of Pediatric Gastroenterology and Nutrition 4, 818-825. 